\title{
Prolonged Scar-in-a-Jar: an in vitro screening tool for anti-fibrotic therapies using biomarkers of extracellular matrix synthesis
}

Sarah Rank Rønnow ${ }^{1,2}$, Rand Qais Dabbagh ${ }^{1}$, Federica Genovese ${ }^{1}$, Carmel B. Nanthakumar ${ }^{3}$, Vikki J. Barrett ${ }^{3}$, Robert B. Good ${ }^{3}$, Sarah Brockbank ${ }^{4,5}$, Simon Cruwys ${ }^{4,6}$, Henrik Jessen ${ }^{1}$, Grith Lykke Sorensen²,

Morten Asser Karsdal ${ }^{1}$, Diana Julie Leeming ${ }^{1}$ and Jannie Marie Bülow Sand ${ }^{1 *}$ (D)

\begin{abstract}
Background: Idiopathic pulmonary fibrosis (IPF) is a rapidly progressing disease with challenging management. To find novel effective therapies, better preclinical models are needed for the screening of anti-fibrotic compounds. Activated fibroblasts drive fibrogenesis and are the main cells responsible for the accumulation of extracellular matrix (ECM). Here, a prolonged Scar-in-a-Jar assay was combined with clinically validated biochemical markers of ECM synthesis to evaluate ECM synthesis over time. To validate the model as a drug screening tool for novel antifibrotic compounds, two approved compounds for IPF, nintedanib and pirfenidone, and a compound in development, omipalisib, were tested.
\end{abstract}

Methods: Primary human lung fibroblasts from healthy donors were cultured for 12 days in the presence of ficoll and were stimulated with TGF- $\beta 1$ with or without treatment with an ALK5/TGF- $\beta 1$ receptor kinase inhibitor (ALK5i), nintedanib, pirfenidone or the mTOR/PI3K inhibitor omipalisib (GSK2126458). Biomarkers of ECM synthesis were evaluated over time in cell supernatants using ELISAs to assess type I, III, IV, V and VI collagen formation (PRO-C1, PRO-C3, PRO-C4, PRO-C5, PRO-C6), fibronectin (FBN-C) deposition and a-smooth muscle actin (a-SMA) expression.

Results: TGF- $\beta 1$ induced synthesis of PRO-C1, PRO-C6 and FBN-C as compared with unstimulated fibroblasts at all timepoints, while PRO-C3 and a-SMA levels were not elevated until day 8. Elevated biomarkers were reduced by suppressing TGF- $\beta 1$ signalling with ALK5i. Nintedanib and omipalisib were able to reduce all biomarkers induced by TGF- $\beta 1$ in a concentration dependent manner, while pirfenidone had no effect on a-SMA.

Conclusions: TGF- $\beta 1$ stimulated synthesis of type I, III and VI collagen, fibronectin and a-SMA but not type IV or V collagen. Synthesis was increased over time, although temporal profiles differed, and was modulated pharmacologically by ALK5i, nintedanib, pirfenidone and omipalisib. This prolonged 12-day Scar-in-a-Jar assay utilising biochemical markers of ECM synthesis provides a useful screening tool for novel anti-fibrotic compounds.

Keywords: Scar-in-a-jar, Fibrogenesis, IPF, Fibroblasts, Collagens, Extracellular matrix, Fibrosis, Drug development, In vitro

\footnotetext{
*Correspondence: jsa@nordicbio.com

${ }^{1}$ Nordic Bioscience A/S, Herlev, Herlev Hovedgade 205-207, DK-2730 Herlev, Denmark

Full list of author information is available at the end of the article
}

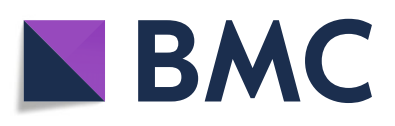

(- The Author(s). 2020 Open Access This article is licensed under a Creative Commons Attribution 4.0 International License, which permits use, sharing, adaptation, distribution and reproduction in any medium or format, as long as you give appropriate credit to the original author(s) and the source, provide a link to the Creative Commons licence, and indicate if changes were made. The images or other third party material in this article are included in the article's Creative Commons licence, unless indicated otherwise in a credit line to the material. If material is not included in the article's Creative Commons licence and your intended use is not permitted by statutory regulation or exceeds the permitted use, you will need to obtain permission directly from the copyright holder. To view a copy of this licence, visit http://creativecommons.org/licenses/by/4.0/. The Creative Commons Public Domain Dedication waiver (http://creativecommons.org/publicdomain/zero/1.0/) applies to the data made available in this article, unless otherwise stated in a credit line to the data. 


\section{Background}

Most drug candidates for pulmonary fibrosis fail in human clinical trials $[1,2]$. To reduce the attrition rates in the clinic it is essential that novel anti-fibrotic compounds are screened in reliable and disease relevant pre-clinical models of fibroproliferative diseases. It is important that these preclinical models replicate key events in human pulmonary fibrosis such as dysregulated fibroblast activity and aberrant remodeling of the extracellular matrix (ECM) [3].

Pulmonary fibrosis includes several lung disorders characterized by the formation of excessive scar tissue in the lungs. Idiopathic pulmonary fibrosis (IPF) is a particularly severe and progressive form [4], with a mean survival of 35 years after the time of diagnosis [5]. The incidence of IPF in Europe and North America has risen in recent years and is estimated to range between 2.8 and 18 cases per 100.000 people per year [6, 7]. During the development of IPF, healthy tissue is replaced by rigid ECM, destroying the lung architecture and leading to disrupted gas exchange and ultimately respiratory failure and death [3]. Transforming growth factor (TGF)- $\beta 1$ plays a critical role in the differentiation of fibroblasts into myofibroblasts, which in turn produce ECM proteins driving the abnormal repair response and scar formation in IPF $[8,9]$. During the progression of fibrosis, ECM alignment and composition is altered [10]. Imbalanced ECM remodelling leads to increased release of tissue- and pathology-specific protein fragments into the circulation [11, 12]. Such protease-generated fragments represent neo-epitopes which can be recognized by specific antibodies employed in enzyme-linked immunosorbent assays (ELISAs) and utilised as biomarkers. Some of these biomarkers have previously been shown to correlate with the progression of IPF [13]. Currently, no circulating biomarkers are routinely used for IPF in the clinic, neither for diagnosis, prognosis, prediction or monitoring. Some of the most commonly studied biomarkers include SP-D and KL6, reflecting epithelial injury; MMP-7, periostin and ECM neo-epitopes such as C1M, C3M, C6M and CRPM reflecting ECM remodelling [14-16].

The first effective disease-modifying drugs to be approved by the U.S. Food and Drug Administration (FDA) and European Medicines Agency (EMA) were pirfenidone and nintedanib, which have succeeded in attenuating lung function decline in patients with IPF $[17,18]$. There is still no cure for IPF, thus new therapeutic options are being explored [19, 20]. One group of therapies that is being tested in clinical trials is inhibitors of the mammalian target of rapamycin (mTOR). These were initially introduced into clinical practice to prevent transplant rejection and later to treat mTOR diseases such as lymphangioleiomyomatosis $[21,22]$. The anti-fibrotic effect of the mTOR inhibitors is mediated by a decrease of type I and III collagen synthesis [23]. Omipalisib (GSK2126458), a potent inhibitor of mTOR and phosphatidylinositol 3-kinase
(PI3K) [24], has been tested in a randomised, placebocontrolled study of IPF, which found that omipalisib has an acceptable tolerability and that target engagement was confirmed (NCT01725139) [25]. Additionally, recent data from a proof of mechanism study indicate that omipalisib reduces collagen synthesis as shown by a rapid decrease of the biomarkers PRO-C3 and PRO-C6 in serum of IPF patients [26]. By using human lung fibroblasts, Woodcock et al. showed that TGF- $\beta 1$ signalling through mTOR is critical for fibrogenesis, by demonstrating that mTOR signalling, was required for type I collagen deposition in vitro [27]. Additional results from precision-cut IPF lung slices confirmed that synthesis of type I collagen, as measured by PRO-C1 ELISA in the supernatants, was mediated through mTOR [27].

Complex in vitro models of fibrogenesis using primary human lung fibroblasts offer a physiologically relevant alternative to in vivo models which may not fully recapitulate the complex pathogenesis exhibited by IPF patients [28, 29]. Cells grown in a crowded, pseudo-3D environment more closely resemble the physiological environment and the pathological ECM compared to standard 2D cell cultures [30]. The Scar-in-a-Jar model developed by Chen et al. [31] uses healthy human lung fibroblasts grown in medium with macromolecules (ficoll or dextran sulphate) to provide crowding conditions. Ficoll contains neutral macromolecules of 70 and $400 \mathrm{kDa}$ that occupy the space in the well, making it unavailable for other molecules and thereby causing the excluded volume effect [32]. These crowded conditions cause increased interactions between the substrate and their respective enzymes, increasing enzymatic activity and accelerating collagen deposition [33]. The use of ficoll allows us to mimic the dense cellular environment within the ECM and improve the release of collagen pro-peptides as compared to systems without crowded conditions. Furthermore, Chen et al. demonstrated that the presence of ficoll leads to a higher degree of cross-linking in the deposited collagen [31], thus better representing in vivo conditions. Ascorbic acid is another crucial component in this model, as it is essential for the post-translational modification of proline to hydroxyproline that allows the correct folding of collagens during synthesis. The addition of human TGF- $\beta 1$ induces fibroblast activation and differentiation to myofibroblasts, increasing ECM production and thereby imitating fibrogenesis [31]. Chen et al. showed that within 6 days the collagen deposition doubled in the Scar-in-a-Jar assay as compared with noncrowded cultures and that the addition of TGF- $\beta 1$ increased the deposition 2-fold as compared with a crowded culture without stimulation. Furthermore, they showed a more aligned pattern of the fibrillar type I collagen and an effect of potential anti-fibrotic compounds on type I collagen deposition. Interestingly, the addition of a crowding agent induced complete cleavage of the type I collagen $\mathrm{C}$ - 
propeptide, whereas the fibroblasts in the non-crowded culture conditions continued to secrete intact procollagen. Recently, Good et al. described a $72 \mathrm{~h}$ high content screening Scar-in-a-Jar assay utilizing fibroblasts from IPF patients, that allowed the quantification of disease-relevant ECM deposition in vitro [34].

Here, a prolonged Scar-in-a-Jar model was used to allow for correct collagen processing, and biochemical markers quantified ECM synthesis for up to 12 days. These markers include PRO-C3 and PRO-C6, biomarkers of type III and VI collagen synthesis, respectively, which have been found to be increased in blood from progressing IPF patients as compared to stable IPF patients in the PROFILE (Prospective Observation of Fibrosis in the Lung Clinical Endpoints) study [35]. In addition, serum levels of a marker of myofibroblasts, alpha-smooth muscle actin $(\alpha$-SMA), has also been shown to be increased in IPF patients compared to healthy controls [36]. The effect of TGF- $\beta 1$ stimulation on ECM synthesis was investigated after 4,8 , and 12 days to determine the kinetics of the different ECM proteins produced. Further, the use of the prolonged Scar-in-a-Jar model as a drug screening tool for novel anti-fibrotic compounds was evaluated by testing nintedanib, pirfenidone and the mTOR/PI3K inhibitor omipalisib. The model is depicted in Fig. 1.

\section{Methods}

\section{Fibroblast cell culture}

Primary human lung fibroblasts in passage 5 and 9 were purchased from Lonza (Basel, Switzerland) (cat. no. CC2512) and kindly provided by GSK (Stevenage, UK). All patients gave full consent and procedures were performed in line with research ethics committee approval. Human biological samples were sourced ethically, and their research use was in accord with the terms of the informed consents under an IRB/EC approved protocol. Cells were grown to confluence and seeded at a density of 30,000 cells/well in 48-well plates in high serum medium $(10 \%$

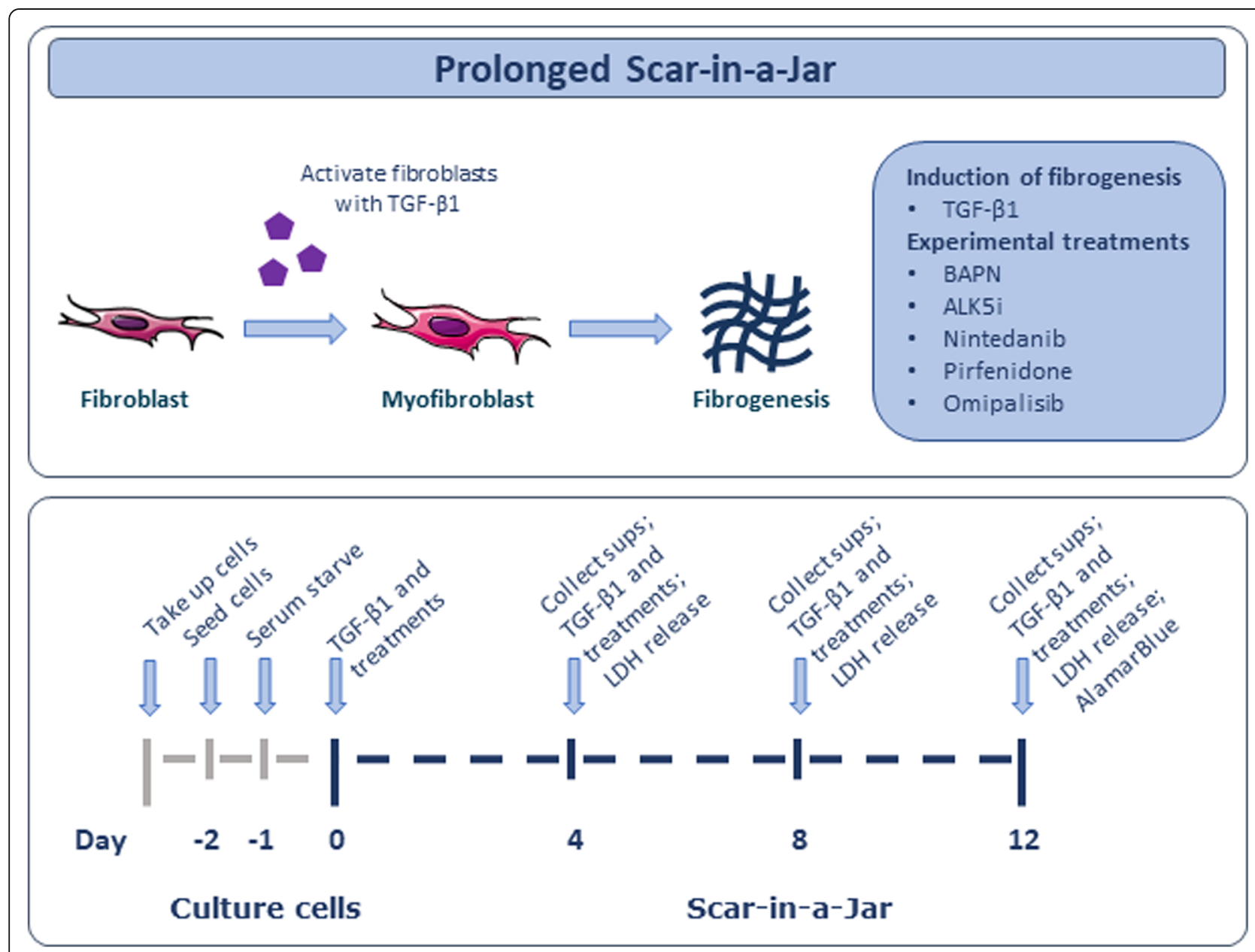

Fig. 1 Prolonged Scar-in-a-Jar as a model of fibrogenesis. Primary lung fibroblasts from healthy donors were cultured in the presence of ficoll to promote a crowded environment. Fibroblasts were stimulated with TGF- $\beta 1$ and differentiated into myofibroblasts that produced high amounts of extracellular matrix proteins. Cells were cultured for 12 days with medium changes at day 4 and 8 
fetal bovine serum (FBS) (cat. no. F7524, Sigma-Aldrich, St. Louise, Missouri, USA) in Dulbecco's modified eagle medium (DMEM) + GlutaMax (cat. no. 31966, Gibco, Life Technologies, Carlsbad, California, USA)) at day -2 . The cells were starved in low serum medium (0.4\% FBS DMEM) at day -1 to avoid interference with biomarker measurements. At day $0,200 \mu \mathrm{L}$ of $1 \mathrm{ng} / \mathrm{mL}$ TGF- $\beta 1$ (cat. no. 100-B-010/CF, R\&D system, Minneapolis, Minnesota, USA) diluted in low serum medium containing ficoll $(56.25 \mathrm{mg} / \mathrm{mL}$ ficoll $70,37.5 \mathrm{mg} / \mathrm{mL}$ ficoll 400 ; cat. no. F2878, Sigma-Aldrich) and 1.5\% L-ascorbic acid, phosphate magnesium salt, n-hydrate (cat. no. 013-19,641, Wako, Osaka, Japan) were added to each well. $100 \mu \mathrm{L}$ of the treatments were added as appropriate: beta-aminopropionitrile (BAPN) (cat. no. A3134, Sigma-Aldrich) in $0.2 \mathrm{mM}$; activin receptor-like kinase 5 (ALK5)/type I TGF- $\beta$ receptor kinase inhibitor (ALK5i) (SB-525334, cat. no. S8822, SigmaAldrich) and nintedanib (cat. no. 656247-17-5, Kemprotec Ltd., Smailthorn, Carnforth, UK) in $1 \mathrm{nM}, 10 \mathrm{nM}, 100 \mathrm{nM}$, $1 \mu \mathrm{M}$ and $10 \mu \mathrm{M}$; pirfenidone (kindly provided by Grünenthal, Aachen, Germany) in 30, 100, 300, 1000 and $3000 \mu \mathrm{M}$; and omipalisib (GSK2126458, cat. no. CTGSK458, Chemietek, Indianapolis, Indiana, USA) in 0.01, $0.1,1,10$ and $100 \mathrm{nM}$. ALK5i, nintedanib and omipalisib were diluted in dimethyl sulfoxide (DMSO) and concentration was kept constant at $0.1 \%$. The corresponding vehicle consisted of $0.1 \%$ DMSO. For pirfenidone, due to solubility issues DMSO content was dependent on pirfenidone concentration and the following concentrations of DMSO were included as vehicles: $0.03,0.1,0.3,1$ and $3 \%$. Cells were incubated at $37{ }^{\circ} \mathrm{C}$ with $95 \% \mathrm{O}_{2}$ and $5 \% \mathrm{CO}_{2}$ and cultured for 12 days. TGF- $\beta 1$ medium and treatments were prepared freshly and exchanged at day 0,4 and 8 . Supernatants from day 4,8 and 12 were stored at $-20^{\circ} \mathrm{C}$ until biomarker assessments by ELISA. Three replicates with four technical replicates testing nintedanib, pirfenidone, ALK5i and omipalisib were performed using the primary fibroblasts from Lonza. The experiment testing BAPN was performed once with four technical replicates using the primary fibroblasts from GSK.

\section{Matrix cleavage}

At day 12, the matrix deposited at the bottom of the wells together with the cells was washed twice with phosphatebuffered saline (PBS) and stored at $-20^{\circ} \mathrm{C}$. Before digestion, the matrix was thawed to room temperature and washed gently with digestion buffer (50 mM TRIS, $36 \mathrm{mM}$ $\mathrm{CaCl}_{2}, \mathrm{pH} 7.5$ ). $200 \mu \mathrm{L}$ of collagenase (cat. no. C9891, Sigma-Aldrich) diluted in digestion buffer $(130 \mu \mathrm{g} / \mathrm{mL})$ was added to each well and incubated at $37^{\circ} \mathrm{C}$ for $24 \mathrm{~h}$. The reaction was stopped by adding $20 \mu \mathrm{L}$ of stop solution (1 tablet of cOmplete Mini Protease Inhibitor Cocktail (cat. no. 11836153001, Roche, Basel, Switzerland) dissolved in $2.5 \mathrm{ml}$ of Milli-Q water).

\section{Metabolic activity assessed by Alamar blue}

To assess the effects of the inhibitors on cell health, Alamar Blue (cat. no. DAL1100, Invitrogen, Carlsbad, California, USA) was used to quantify cellular metabolism at day 0 and 12. In brief, Alamar Blue was diluted 1:10 in low serum medium and $200 \mu \mathrm{L}$ was added to each well and incubated for $2 \mathrm{~h}$ at $37^{\circ} \mathrm{C}$ in $5 \% \mathrm{CO}_{2}$. In the presence of metabolically active cells, resazurin is reduced to fluorescent resorufin, which can be quantified by a colorimetric change and fluorescent signal. After incubation, $160 \mu \mathrm{L}$ was transferred to black 96-well plates and the fluorescence was measured using $540 \mathrm{~nm}$ as excitation wavelength and subtracting the background measured using $590 \mathrm{~nm}$ as emission wavelength on an ELISA reader.

\section{Cytotoxicity assessed by LDH release}

To assess the effects of compound incubation on cytotoxicity, release of lactate dehydrogenase (LDH) from damaged cells was assessed at day 4, 8 and 12 using the Cytotoxicity Detection Kit $^{\text {PLUS }}$ (LDH) (cat. no. 04744934001, Roche) according to the manufacturer's instructions. In brief, $50 \mu \mathrm{L}$ of cell supernatant was mixed with $50 \mu \mathrm{L}$ of reaction mixture in uncoated, clear, flat bottomed 96-well plates. Plates were incubated for $30 \mathrm{~min}$ at $20^{\circ} \mathrm{C}$ in the dark, shaking $300 \mathrm{rpm}$, followed by $25 \mu \mathrm{L}$ stop solution. Absorbance was measured at $492 \mathrm{~nm}$ with $690 \mathrm{~nm}$ as a reference on an ELISA reader, subtracting the background. To determine the maximum LDH release possible, one well with cells treated with TGF- $\beta 1$ was lysed at day 4,8 and 12 , using $200 \mu \mathrm{L}$ of lysis solution diluted 1:20 in low serum medium and allowed to incubate for $15 \mathrm{~min}$ at $37^{\circ} \mathrm{C}$ in $5 \% \mathrm{CO}_{2}$ (lysis control).

\section{Biomarker measurements}

Collagen synthesis, fibronectin and $\alpha$-SMA were evaluated in cell supernatants collected at day 4, 8, and 12 using specific competitive ELISAs (Nordic Bioscience, Herlev, Denmark). The PRO-C1 assay (cat. no. 2800) measures the N-terminal pro-peptide of type I collagen, describing the formation of type I collagen [37]. The PRO-C3 assay (cat. no. 1700) measures the neo-epitope of the N-terminal pro-peptide of type III collagen after cleavage from the pro-collagen molecule and describes the formation of type III collagen [38]. The PRO-C4 assay (cat. no. 8000) measures an internal epitope in the 7S domain of type IV collagen [39]. The PRO-C5 assay (cat. no. 3000) measures the neo-epitope of the Cterminal pro-peptide of type $\mathrm{V}$ collagen after cleavage from the pro-collagen molecule and describes the formation of type $\mathrm{V}$ collagen [40, 41]. The PRO-C6 assay (cat. no. 4000) measures the C-terminal of the released C5 domain of the type VI collagen $\alpha 3$ chain, also referred to as endotrophin, and describes the formation of type VI collagen [42]. The FBN-C assay (cat. no. N101-00) 
measures the C-terminal of fibronectin [43] and the $\alpha$ SMA assay (cat. no. N132-00) measures the acetylated Nterminal of $\alpha$-SMA [36]. The detailed protocols for each assay can be found in the specific references. Furthermore, $\alpha$ CTX-1 (Alpha CrossLaps ${ }^{\circ}$ (CTX-I) ELISA, cat. no. AC04F1, Immunodiagnostic System Nordic A/S, Copenhagen, Denmark), a marker of type I collagen cross-linking, was assessed in the cleaved matrix at day 12 .

\section{Staining}

Primary human lung fibroblasts (cat. no. CC-2512, Lonza) were grown to confluence and seeded at a density of 22,000 cells/well in 8-well EZ glass slides (cat. no. PEZGS0816, Millipore, Massachusetts, USA) and cultivated for 12 days following the procedure described in "fibroblast cell culture". Fibroblasts were unstimulated (control) or stimulated with TGF- $\beta 1$. The wells were washed three times with PBS followed by fixation with $4 \%$ formaldehyde (Sigma-Aldrich) for $2 \mathrm{~h}$. The fixed cells were washed three times with PBS before adding $300 \mu \mathrm{L}$ peroxidase for $10 \mathrm{~min}$. The wells were washed once with PBS and blocked with $300 \mu \mathrm{L} 2 \%$ skim milk diluted in PBS for 15 min before adding $300 \mu \mathrm{L}$ of monoclonal mouse antibody targeting type I and III collagen (cat. no. Ab6308 and Ab6310, Abcam, Cambridge, UK) or $\alpha$-SMA (cat. no. Ab7817, Abcam) diluted 1:100 in 2\% skim milk and incubated overnight. The wells were washed three times with PBS and incubated with $300 \mu \mathrm{L}$ of HRPlabelled goat anti-mouse antibody (cat. no. K4001, Dako, Glostrup, Denmark) for $30 \mathrm{~min}$. Wells were washed 3 times with PBS before adding $300 \mu \mathrm{L}$ of substrate $(1$ drop of chromogen diluted in $1 \mathrm{~mL}$ substrate buffer; cat. no. K3468, Dako) and incubated for 1-15 min until color change was evident. Wells were washed 3 times with PBS and counterstained with Mayer's hematoxylin (1.5 g hematoxylin, $0.2 \mathrm{~g}$ sodium iodate, $50 \mathrm{~g}$ potassium aluminum sulfate, $1 \mathrm{~g}$ citric acid monohydrate and $1 \mathrm{~L}$ MilliQ water) for $12 \mathrm{~s}$ and rinsed with tap-water before allowing to dry. All the steps were performed at room temperature. Pictures of $\times 10$ magnification were obtained using an Olympus DP71 digital camera connected to an Olympus BX60 microscope.

\section{Statistical analysis}

Statistical significance was determined using t-test or two-way ANOVA with Sidak's or Dunnett's multiple comparisons test. Data are plotted as raw values or percentage of the TGF- $\beta 1$ control or lysis control. Data are presented as mean \pm SD of 3 separate experiments each with 4 replicates/treatment. Treatment data are plotted as line graphs comparing biomarker data from day 4,8 and 12 or vehicle and treatment. All statistical tests were performed in GraphPad Prism software v.6 (GraphPad Software, San Diego, CA). P-values lower than 0.05 were considered significant.

\section{Results}

The fibrogenic potential of lung fibroblasts stimulated with TGF- $\beta 1$

The fibrogenic potential of lung fibroblasts was evaluated by assessing ECM production in response to TGF- $\beta 1$ by assessing biomarkers of type I (PRO-C1), III (PRO-C3), IV (PRO-C4), V (PRO-C5) and VI (PRO-C6) collagen synthesis as well as fibronectin (FBN-C) in cell supernatants. Additionally, the expression of $\alpha$-SMA, a marker of the activated myofibroblast, was assessed. After 4 days of culture, fibroblasts stimulated with TGF- $\beta 1$ produced significantly higher levels of type I collagen (PRO-C1; 4-fold, $P<0.05$; Fig. 2a), type VI collagen (PRO-C6; 3 -fold, $\mathrm{P}<$ 0.05; Fig. 2e) and fibronectin (FBN-C; 3 -fold, $\mathrm{P}<0.05$; Fig. 2f) as compared to unstimulated cells, and peaked at day 8 with $8-(P=0.001), 5-(P=0.1)$ and 5-fold $(P=$ 0.0004 ) increases, respectively, and remained elevated until day 12. Production of type III collagen (PRO-C3; Fig. 2b) and $\alpha$-SMA (Fig. 2g) were at the level of unstimulated cells at day 4 and increased 9- $(P=0.08)$ and 4-fold $(P=0.01)$ at day 8 and additionally to $23-(P=0.04)$ and 5 fold $(P=0.0008)$, respectively, at day 12 . Type IV (PROC4) and V (PRO-C5) collagen production was not affected by TGF- $\beta 1$ stimulation, and levels remained constant throughout the experiment (Fig. 2c-d).

To further characterize the model, we stained for $\alpha$ SMA as a marker of fibroblast activation and the two most prominent collagens, type I and III, to visualize the ECM deposition at day 12 (Fig. 2h). Type I collagen fibrils were clearly visible in the ECM surrounding fibroblasts stimulated with TGF- $\beta 1$, whereas wells with unstimulated fibroblasts contained small amounts of type I collagen staining. TGF- $\beta 1$ stimulation also induced type III collagen synthesis, albeit to a lesser degree. Staining of $\alpha$-SMA showed a slight activation of unstimulated cells, possibly caused by them growing on plastic, but TGF- $\beta 1$ stimulation increased the signal dramatically.

\section{Collagen cross-linking occurs in the prolonged Scar-in-a- Jar model and can be modulated}

Collagen cross-linking is a key feature of fibrogenesis. To determine whether collagen cross-linking occurs in this assay fibroblasts were stimulated with TGF- $\beta 1$ in the presence or absence of the pan-lysyl oxidase (LOX) inhibitor BAPN. Cross-linking was evaluated by assessing $\alpha$ CTX-I, a marker of cross-linking in the Cterminal telopeptide of type I collagen, in collagenasecleaved matrix (Fig. 3). Matrix originating from fibroblasts stimulated with TGF- $\beta 1$ had significantly higher levels of $\alpha \mathrm{CTX}-\mathrm{I}$ as compared with matrix from unstimulated fibroblasts $(P=0.007)$, indicating that collagen cross-linking does occur in the prolonged Scar-in-aJar model. In addition, TGF- $\beta 1$ stimulation combined with BAPN treatment significantly reduced $\alpha \mathrm{CTX}-\mathrm{I}$ 


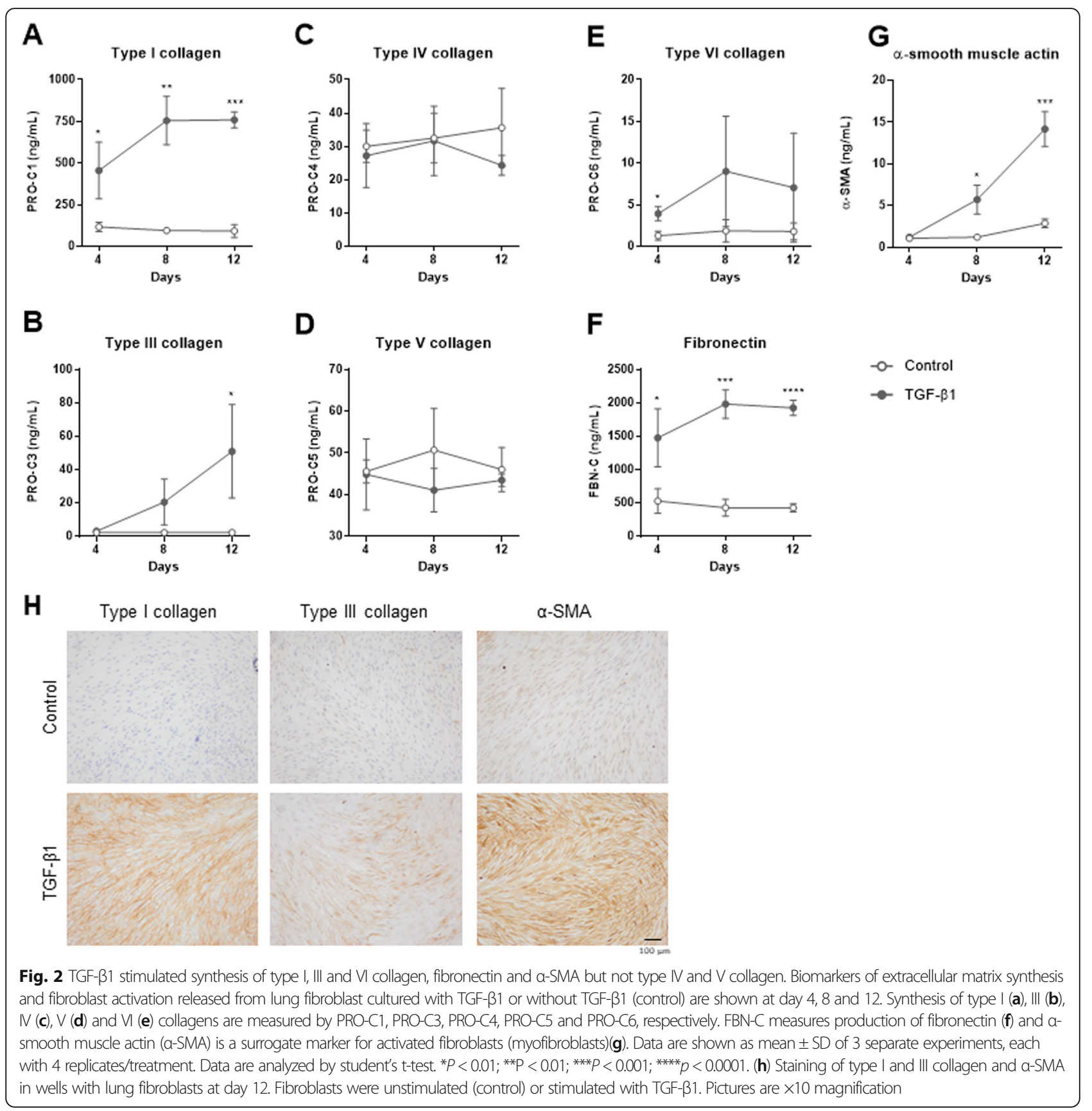

levels by 6-fold compared to untreated fibroblasts stimulated with TGF- $\beta 1$ only $(p<0.0001)$, indicating that cross-linking may be modified in this model.

\section{The fibrogenic response can be modulated by inhibiting TGF- $\beta 1$ signaling}

To investigate whether fibrogenesis could be modulated in this system, the TGF- $\beta 1$ receptor kinase inhibitor ALK5i, known to inhibit collagen production, was used at five different concentrations on TGF- $\beta 1$-stimulated fibroblasts as a positive control and its effects on ECM synthesis was evaluated. ALK5i had a concentration-dependent effect on the metabolic activity measured by Alamar Blue, with significant decreases after treatment with $100 \mathrm{nM}(88 \%, P=$ $0.0084), 1 \mu \mathrm{M}(71 \%, P<0.0001)$ and $10 \mu \mathrm{M}(62 \%, \mathrm{P}<$ 0.0001) ALK5i as compared with vehicle (95\%; Fig. 4a). However, a minimal LDH release $(P=0.7)$ indicated that the cytotoxic effect of ALK5i was negligible (Fig. 4b). ALK5i concentration-dependently and significantly lowered the levels of PRO-C1, PRO-C6 and FBN-C at all days (Fig. 4c, 


\section{Collagen cross-linking}

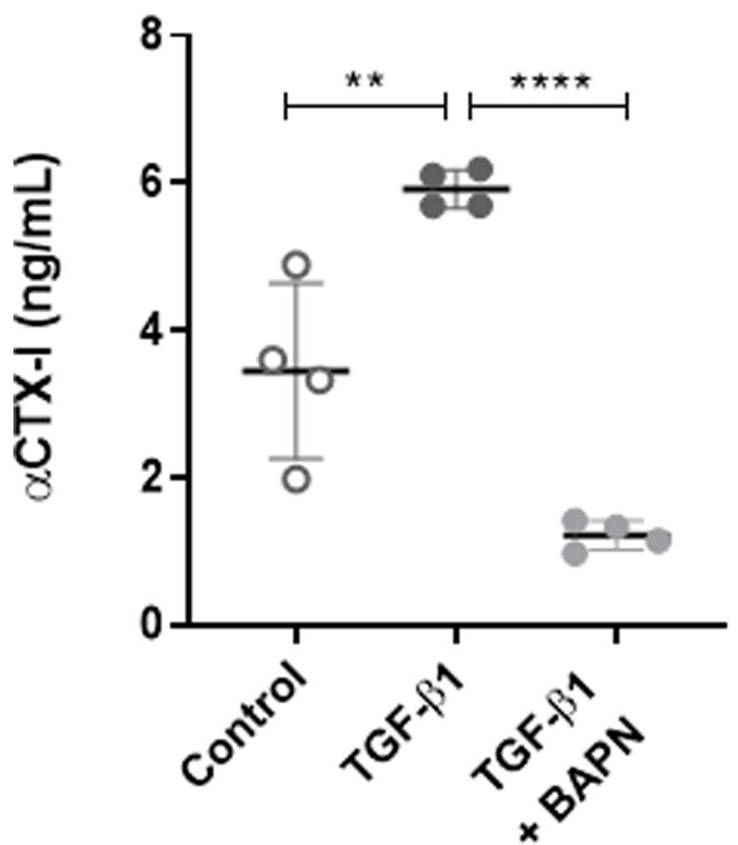

Fig. 3 TGF- $\beta 1$ induced collagen cross-linking which could be modulated by a LOX inhibitor. Levels of type I collagen cross-linking (aCTX-I) were assessed in collagenase-cleaved matrix produced by lung fibroblasts on day 12. Fibroblasts were cultured without stimulation (control), with TGF- $\beta 1$ alone or with TGF- $\beta 1$ and the pan-lysyl oxidase (LOX) inhibitor beta-aminopropionitrile (BAPN). Data are shown as mean \pm SD of 4 replicates and analyzed by student's t-test comparing TGF- $\beta 1$ to control or TGF- $\beta 1+$ BAPN. ${ }^{* *} \mathrm{P}<0.01$; ${ }^{* * *} P<0.0001$

e, f). An effect on PRO-C3 and $\alpha$-SMA was seen on day 8 and 12 , but not on day 4 where production was not initiated (Fig. 4d, g).

\section{Effect of anti-fibrotic compounds on ECM synthesis in the prolonged Scar-in-a-Jar model}

To further evaluate the prolonged Scar-in-a-Jar model, the potency of anti-fibrotic compounds in the clinic or in development were tested. Fibroblasts stimulated with TGF- $\beta 1$ were treated with nintedanib, pirfenidone, or omipalisib and the ECM biomarkers that were found to respond to TGF- $\beta 1$ stimulation were assessed in supernatant collected at day 4,8 and 12 to evaluate the antifibrotic effects on fibroblasts.

Nintedanib significantly decreased metabolic activity, as determined by Alamar Blue, as compared to vehicle at concentrations of $100 \mathrm{nM}, 1 \mu \mathrm{M}$ and $10 \mu \mathrm{M}$ to 75,63 and $0 \%$, respectively (all $P<0.0001$ ), of the TGF- $\beta 1$ control (Fig. 5a). LDH release was not significantly changed in response to nintedanib, however at the highest concentration $(10 \mu \mathrm{M})$ showed a small trend for elevated LDH release (Fig. 5b). Based on the 100\% reduction in Alamar
Blue for the highest concentration of nintedanib, we omitted this concentration in the following biomarker analyses. Nintedanib concentration-dependently decreased PRO-C1, PRO-C6 and FBN-C at all days with largest effects observed at day 12 where levels decreased to 46, 25 and 16\% of the TGF- $\beta 1$ control as compared with the respective vehicle controls (102, 102 and 84\%) (Fig. 5c, e, f). PRO-C3 and $\alpha-$ SMA levels were not altered at day 4 where production of these had not initiated, but were decreased in response to nintedanib at day 8 and 12 to 31\% for PRO-C3 and 34\% for $\alpha$-SMA of the TGF- $\beta 1$ control at day 8 as compared with the vehicle controls (103 and 95\%) (Fig. 5d, g).

Pirfenidone at the highest concentration used $(3000 \mu \mathrm{M})$ and its corresponding vehicle ( $3 \%$ DMSO) both decreased Alamar Blue to $3 \%$ of the TGF- $\beta 1$ control $(P<0.0001$; Fig. 6a), and there was no difference between pirfenidone and its vehicle at any concentrations. LDH release was significantly increased in response to pirfenidone treatment at concentrations above $300 \mu \mathrm{M}(21 \%$ vs. $18 \%, P=0.004)$. At $3000 \mu \mathrm{M}, \mathrm{LDH}$ release increased to 53 and $52 \%$ of the lysis control for pirfenidone and its vehicle control, respectively (Fig. 6b). These results indicate that the solvent (increasing concentrations of DMSO) had a significant toxic effect on the cells which almost completely abolish metabolic activity at the highest concentration (3\%). However, the cytotoxic effect was slightly but significantly higher for pirfenidone as compared to vehicle ( 0.3 and $1 \%$ DMSO) at concentrations of 300 and $1000 \mu \mathrm{M}$, indicating a mild cytotoxic effect of pirfenidone. Thus, based on the $97 \%$ reduction in metabolic activity and a significant increase in LDH release, the highest concentration of pirfenidone was omitted in the following biomarker analyses. Here, data are presented which compare one concentration of pirfenidone $(1000 \mu \mathrm{M})$ to vehicle ( $1 \%$ DMSO) over time. No effects were seen for concentrations of pirfenidone below $300 \mu \mathrm{M}$. Graphs showing all concentrations of pirfenidone are included in Supplementary Figure 1 . At day 4, no difference between pirfenidone and vehicle was observed for PRO-C1, PRO-C3, FBN-C or $\alpha$-SMA (Fig. 6c, d, f, g). Only PRO-C6 showed a significant difference $(P<0.01)$, with decreases of PRO-C6 levels for $1000 \mu \mathrm{M}$ pirfenidone of $50 \%$ as compared with $60 \%$ for vehicle (Fig. 6e). At day 8 and 12, pirfenidone significantly decreased levels of PRO-C1 $(P=0.002$ and 0.02$)$, PRO-C6 $(P=0.02$ and 0.002$)$ and FBN-C $(P<0.0001$ and $P=0.01$ ), while $\mathrm{PRO}-\mathrm{C} 3$ was only significantly decreased at day $8(P=0.005)$ as compared to vehicle. Pirfenidone had no effect on $\alpha$-SMA levels as compared to vehicle at any timepoint.

Omipalisib significantly decreased metabolic activity to $48 \%$ of the TGF- $\beta 1$ control at the highest concentration $(100 \mathrm{nM})$ as compared to $100 \%$ for the vehicle $(\mathrm{P}<0.0001$; Fig. 7a). Additionally, $100 \mathrm{nM}$ omipalisib significantly increased LDH release to $12 \%$ of the lysis control as compared to $6 \%$ for the vehicle ( $P=0.0003$; Fig. $7 \mathrm{~b})$. Omipalisib 

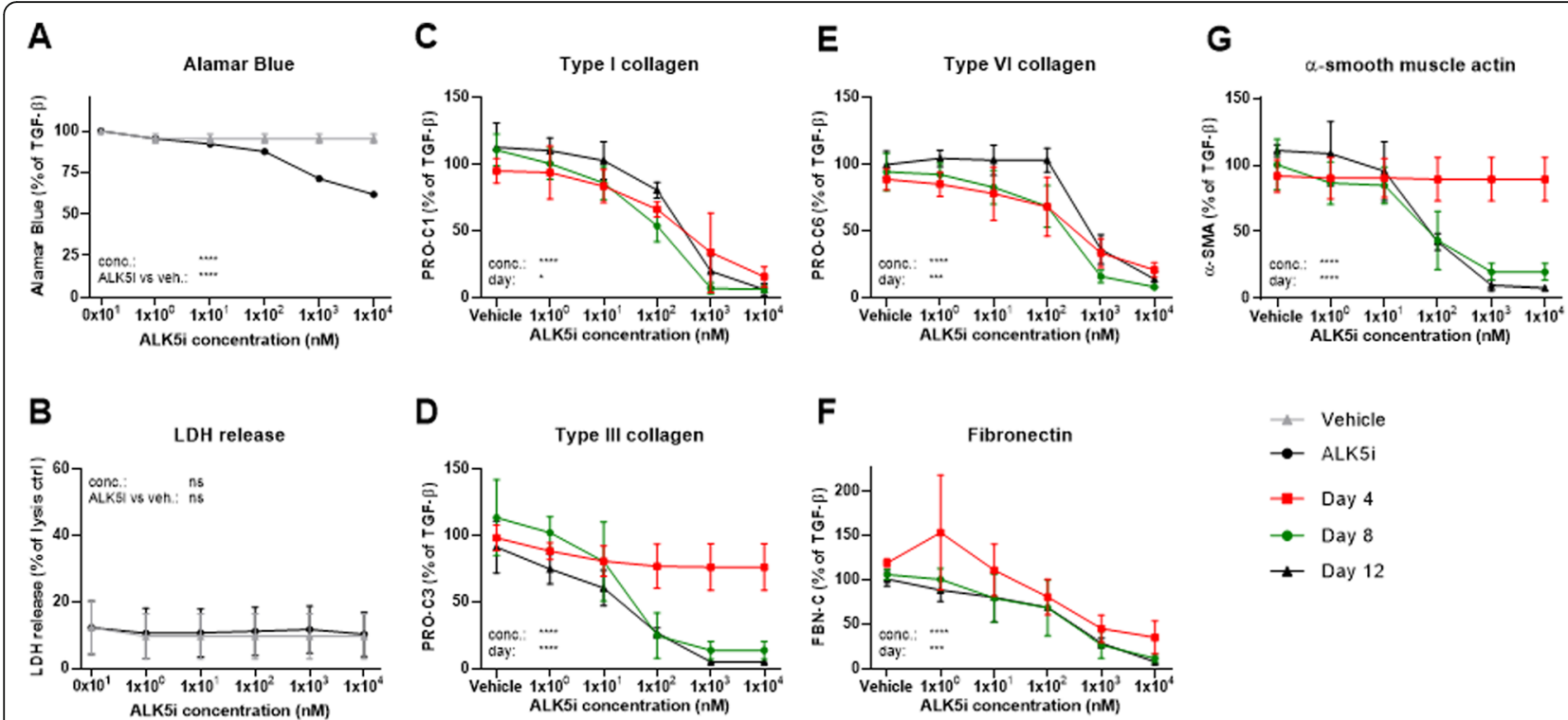

Fig. 4 Inhibition of TGF- $\beta 1$ signaling by an ALK5 inhibitor reduced fibrogenesis. Lung fibroblasts were stimulated with TGF- $\beta 1$ and treated with $1 \times$ $10^{0}, 1 \times 10^{1}, 1 \times 10^{2}, 1 \times 10^{3}$ or $1 \times 10^{4} \mathrm{nM}$ activin receptor-like kinase 5 (ALK5)/type I TGF- $\beta$ receptor kinase inhibitor (ALK5i) or vehicle (0.1\% DMSO). a Metabolic activity was assessed by Alamar Blue at day 12 and data are presented as percentages of the TGF- $\beta 1$ control for vehicle and ALK5i. $\mathbf{b}$ Cytotoxicity was assessed by lactate dehydrogenase (LDH) release at day 4 and data are presented as percentage of the maximum $L D H$ release determined by cell lysis for vehicle and ALK5i. $\mathbf{c}-\mathbf{g}$ Biomarkers of ECM synthesis (type I (PRO-C1), III (PRO-C3) and VI (PRO-C6) collagen and fibronectin (FBN-C)) and fibroblast activation (a-SMA) were measured in the supernatant at day 4, 8 and 12. Data are presented as percentage of the TGF- $\beta 1$ control for day 4,8 , and 12. All data are shown as mean \pm SD of 3 separate experiments each with 4 replicates/treatment and analyzed by two-way ANOVA with Sidak's or Dunnett's multiple comparisons test comparing ALK5i to vehicle. ${ }^{*} P<0.05$; ${ }^{* *} P<0.01 ;{ }^{* * *} P<0.001 ;{ }^{* * * *} P<0.0001$

concentration-dependently reduced all biomarker levels (Fig. 7c-g) with the largest effects observed for PRO-C3, PRO-C6 and $\alpha$-SMA where levels were reduced to 22,18 and $16 \%$, respectively, of the TGF- $\beta 1$ control at day 12 as compared with the respective vehicle controls (83, 92 and $94 \%)$. PRO-C3 and $\alpha$-SMA levels were not altered at day 4 where production of these had not initiated, and for the other biomarkers, effects at day 4 were more modest than at later timepoints.

\section{Discussion}

Many anti-fibrotic drug candidates fail when entering clinical trials, despite promising results obtained in a pre-clinical setting. This suggests that improved preclinical assays are needed to successfully translate the preclinical results to the clinical setting. Here, we propose a novel tool for drug screening that has the potential to aid the anti-fibrotic drug development process. We developed a prolonged Scar-in-a-Jar in vitro model and combined the assay with the measurement of clinically validated biomarkers of ECM synthesis in the cell supernatant. The model was validated by testing first a TGF- $\beta 1$ receptor kinase inhibitor, and subsequently the two FDA approved anti-fibrotic compounds nintedanib and pirfenidone together with a mTOR/PI3K inhibitor in development, omipalisib. We found that stimulating primary lung fibroblasts with TGF- $\beta 1$ increased the
ECM synthesis and $\alpha$-SMA expression over time, and that this was modulated by anti-fibrotic treatments in a concentration dependent manner.

Currently, many in vitro models only allow investigations of fibrogenesis in acute studies of 1-3 days [28, 34] although some models extend to a few weeks [44]. To our knowledge, this is the first time that a 12 days fibroblast culture has been combined with the investigation of ECM synthesis in the supernatant. The prolonged culture allows investigation of a drug in a system which is not limited to the acute response. In this study we investigated the ECM production after 4, 8 and 12 days of fibroblast culture, and observed that synthesis of different proteins occur at different times. Interestingly, type III collagen and $\alpha$-SMA synthesis was not evident at day 4 but increased with TGF- $\beta 1$ stimulation at day 8 and even more so at day 12 . Levels of type I collagen and fibronectin peaked at day 8 and stayed elevated at day 12 , while remaining biomarkers continued to increase over the whole course of the experiment. This could indicate that there is a continuous activation of fibroblasts and additive contribution to the ECM synthesis throughout the 12-day period. In the prolonged Scar-in-a-Jar model, TGF- $\beta 1$ significantly induced accumulation of type I (PRO-C1), III (PRO-C3) and VI (PRO-C6) collagen, fibronectin (FBN-C) and $\alpha$-SMA in comparison to unstimulated cells but did not stimulate type IV (PRO-C4) 

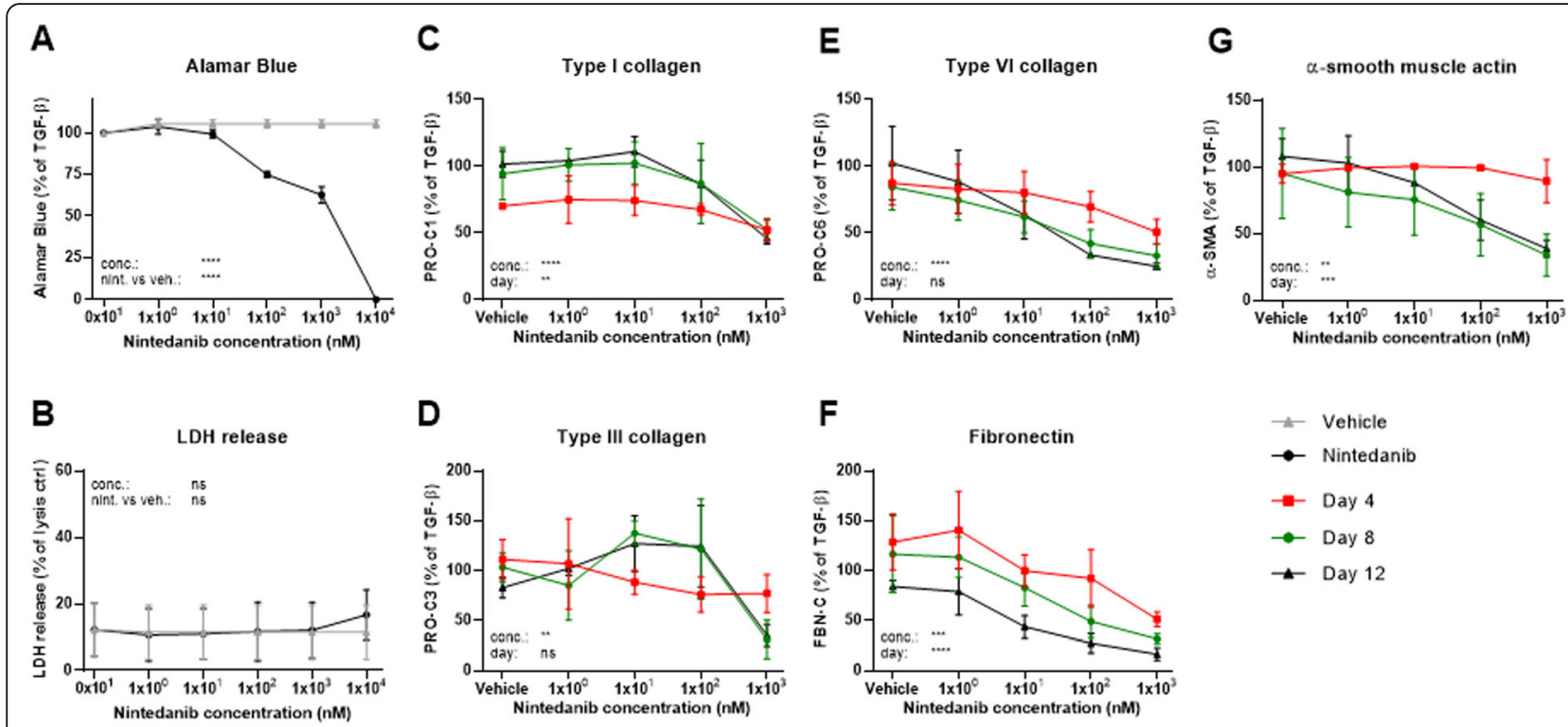

Fig. 5 Nintedanib reduced fibrogenesis and effects were more evident at later timepoints. Lung fibroblasts were stimulated with TGF- $\beta 1$ and treated with $1 \times 10^{0}, 1 \times 10^{1}, 1 \times 10^{2}, 1 \times 10^{3}$ or $1 \times 10^{4} \mathrm{nM}$ nintedanib or vehicle (0.1\% DMSO). a Metabolic activity was assessed by Alamar Blue at day 12 and data are presented as percentages of the TGF- $\beta 1$ control for vehicle and nintedanib. $\mathbf{b}$ Cytotoxicity was assessed by lactate dehydrogenase $(\mathrm{LDH})$ release at day 4 and data are presented as percentage of the maximum LDH release determined by cell lysis for vehicle and nintedanib. c-g Biomarkers of ECM synthesis (type I (PRO-C1), III (PRO-C3) and VI (PRO-C6) collagen and fibronectin (FBN-C)) and fibroblast activation (a-SMA) were measured in the supernatant at day 4, 8 and 12. Data are not shown for the highest concentration of nintedanib which significantly reduced Alamar Blue. Data are presented as percentage of the TGF- $\beta 1$ control for day 4, 8, and 12. All data are shown as mean \pm SD of 3 separate experiments each with 4 replicates/treatment and analyzed by two-way ANOVA with Sidak's or Dunnett's multiple comparisons test comparing nintedanib to vehicle. ns non-significant; ${ }^{*} P<0.05 ;{ }^{* *} P<0.01$; ${ }^{* *} P<0.001$; ${ }^{* * *} P<0.0001$

or V (PRO-C5) collagen production. Type I and III collagen are the main ECM proteins associated with fibrogenesis, and TGF- $\beta 1$ has previously been identified as a stimulator of type I and III collagen production by lung fibroblasts in vitro [45]. In line with our data, Walker et al. observed a small increase in fibronectin expression in airway fibroblasts in response to TGF- $\beta$ stimulation after one day of culture while the increase was more pronounced after 20 days [44]. This underlines the importance of the temporal aspect when investigating fibrotic processes. Normally, fibroblasts do not produce type IV collagen, but Roach et al. showed that myofibroblasts had increased type IV collagen mRNA expression upon stimulation with TGF- $\beta 1$ [46]. Tuan et al. demonstrated that fibroblasts in a fibroplasia model were able to produce type $\mathrm{V}$ collagen, albeit to a much smaller extent than type I collagen [47]. Additionally, Knüppel et al. observed that TGF- $\beta$ stimulation of primary fibroblasts resulted in increased type $\mathrm{V}$ collagen mRNA expression and protein concentration [48]. This indicates that the conditions in the prolonged Scar-in-a-Jar model are not favorable for the production of type IV and V collagen, or that amounts are too small to observe. Using a different fibrogenic stimuli, e.g. platelet-derived growth factor (PDGF), may induce fibrogenesis with a different ECM protein profile. Furthermore, the degree of collagen cross-linking in the prolonged Scar-in-a-Jar model was significantly elevated by TGF- $\beta 1$ stimulation and could be abolished by a pan-LOX inhibitor. Hence, providing a model which could be used to investigate the effects of current anti-fibrotic compounds on collagen cross-linking, an effect which could promote fibrolysis and be beneficial for patients with pulmonary fibrosis.

ALK5i, an inhibitor of the type I TGF- $\beta$ receptor kinase, was able to significantly decrease the TGF- $\beta 1$ induced levels of PRO-C1, PRO-C3, PRO-C6, FBN-C, and $\alpha$-SMA. Thus, the pro-fibrotic effects that TGF- $\beta 1$ exerts on lung fibroblasts can be modulated in this system, and the combination of the prolonged Scar-in-a-Jar model and biochemical markers of ECM synthesis may be a useful tool for evaluating anti-fibrotic compounds. In line with this, Epstein et al. showed that an ALK5i was able to reduce $\alpha$-SMA and type I collagen mRNA levels after $24 \mathrm{~h}$ in normal fibroblasts cultivated in an IPF conditioned matrix [49].

Nintedanib and omipalisib were able to modulate fibrogenesis in the prolonged Scar-in-a-Jar model as evident by a significant decrease of PRO-C1, PRO-C3, PRO-C6, FBN-C and $\alpha$-SMA levels in supernatant. In line with the current results, Gao et al. showed that an mTOR inhibitor was able to significantly reduce TGF- $\beta 1$ 

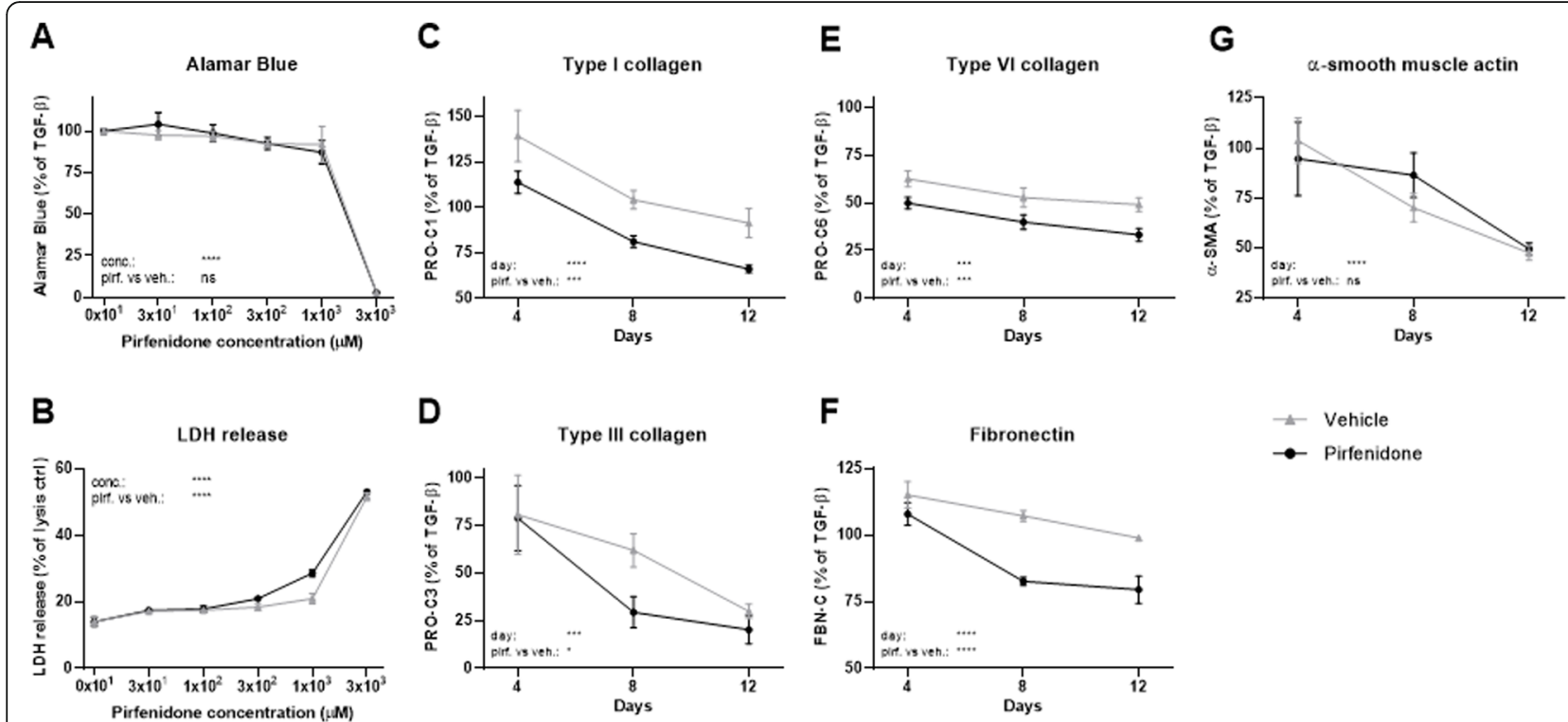

Fig. 6 Pirfenidone reduced matrix protein synthesis but had no effect on fibroblast activation. Lung fibroblasts were stimulated with TGF- $\beta 1$ and treated with $3 \times 10^{1}, 1 \times 10^{2}, 3 \times 10^{2}, 1 \times 10^{3}$ or $3 \times 10^{3} \mu \mathrm{M}$ pirfenidone or corresponding vehicle $(0.03,0.1,0.3,1 \%$ or $3 \%$ DMSO). a Metabolic activity was assessed by Alamar Blue at day 12 and data are presented as percentages of the TGF- $\beta 1$ control for vehicle and pirfenidone. $\mathbf{b}$ Cytotoxicity was assessed by lactate dehydrogenase ( $\mathrm{LDH}$ ) release at day 4 and data are presented as percentage of the maximum $\mathrm{LDH}$ release determined by cell lysis for vehicle and pirfenidone. c-g Biomarkers of ECM synthesis (type I (PRO-C1), III (PRO-C3) and VI (PRO-C6) collagen and fibronectin (FBN-C)) and fibroblast activation (a-SMA) were measured in the supernatant at day 4,8 and 12 . Data are shown for $1 \times 10^{3} \mu \mathrm{M}$ pirfenidone and its corresponding vehicle and are presented as percentage of the TGF- $\beta 1$ control over time. All data are shown as mean \pm SD of 3 separate experiments each with 4 replicates/treatment and analyzed by two-way ANOVA with Sidak's multiple comparisons test comparing pirfenidone to vehicle at day 4, 8 and 12. ns non-significant; ${ }^{*} \mathrm{P}<0.05$; ${ }^{* * P}<0.01$; ${ }^{* * P} \mathrm{P}<0.001$; ${ }^{* * * P}<0.0001$

induced type III collagen and fibronectin expression within $24 \mathrm{~h}$ in primary human lung fibroblasts [23]. Studies using precision-cut IPF lung slices have shown that omipalisib is also capable of modulating the accumulation of $\mathrm{PRO}-\mathrm{C} 1$ from fibrotic lung tissue in an ex vivo setting [24, 27]. Additionally, a proof of mechanism study showed that treatment of IPF patients with omipalisib for only 7-10 days significantly reduced serum levels of PRO-C3 and PRO-C6, and that these levels correlated with levels of omipalisib in plasma [26]. Nintedanib has been shown to decrease TGF- $\beta 1$ induced collagen secretion from IPF fibroblasts and non-fibrotic control fibroblasts within $48 \mathrm{~h}$ [50]. Nintedanib was also able to prevent an increase in type I collagen mRNA when added to normal fibroblasts cultured for $24 \mathrm{~h}$ in an IPF conditioned matrix [49]. These data indicate that mTOR inhibitors and nintedanib have direct effects on the fibroblasts producing collagens and other ECM proteins. Our results indicated that both nintedanib and omipalisib may have cytotoxic effects on the fibroblasts at high concentrations. There was a clear effect on Alamar Blue and partially on LDH release in response to these compounds, indicating a reduction in cell metabolic activity, and a concurrent increase in cytotoxicity, both of which could be beneficial at the correct dose in a fibrotic setting.
In spite of a pronounced effect of the solvent at high concentrations, a reduction of PRO-C1, PRO-C3, PROC6 and FBN-C, but not $\alpha$-SMA, was observed in response to pirfenidone treatment after 8 and 12 days of culture. Interestingly, after 4 days of culture, only PROC6 levels were significantly reduced by pirfenidone as compared with vehicle. Pirfenidone at concentrations of 300 and $1000 \mu \mathrm{M}$ had small but significant cytotoxic effects, as determined by LDH release, as compared to the solvent alone, while metabolic activity assessed by Alamar Blue was not altered. The biomarker data showed no effect on $\alpha$-SMA assessed in cell supernatant which could indicate that pirfenidone does not alter fibroblast activation but may have a beneficial effect on ECM synthesis. The anti-fibrotic and anti-inflammatory effects of pirfenidone have not been fully established [51]. Some studies have shown that pirfenidone had a direct effect on fibroblasts, whereas others indicated that the effect was very weak $[49,52-55]$. However, these studies were performed for a shorter period of 1-2 days which may influence the effect on protein synthesis, as indicated by our results. In a study of IPF fibroblasts, Knüppel et al. found nintedanib to reduce gene expression of type I collagen and fibronectin and attenuate the secretion of type I and III collagen, whereas pirfenidone showed less pronounced effects even in concentrations of up to 


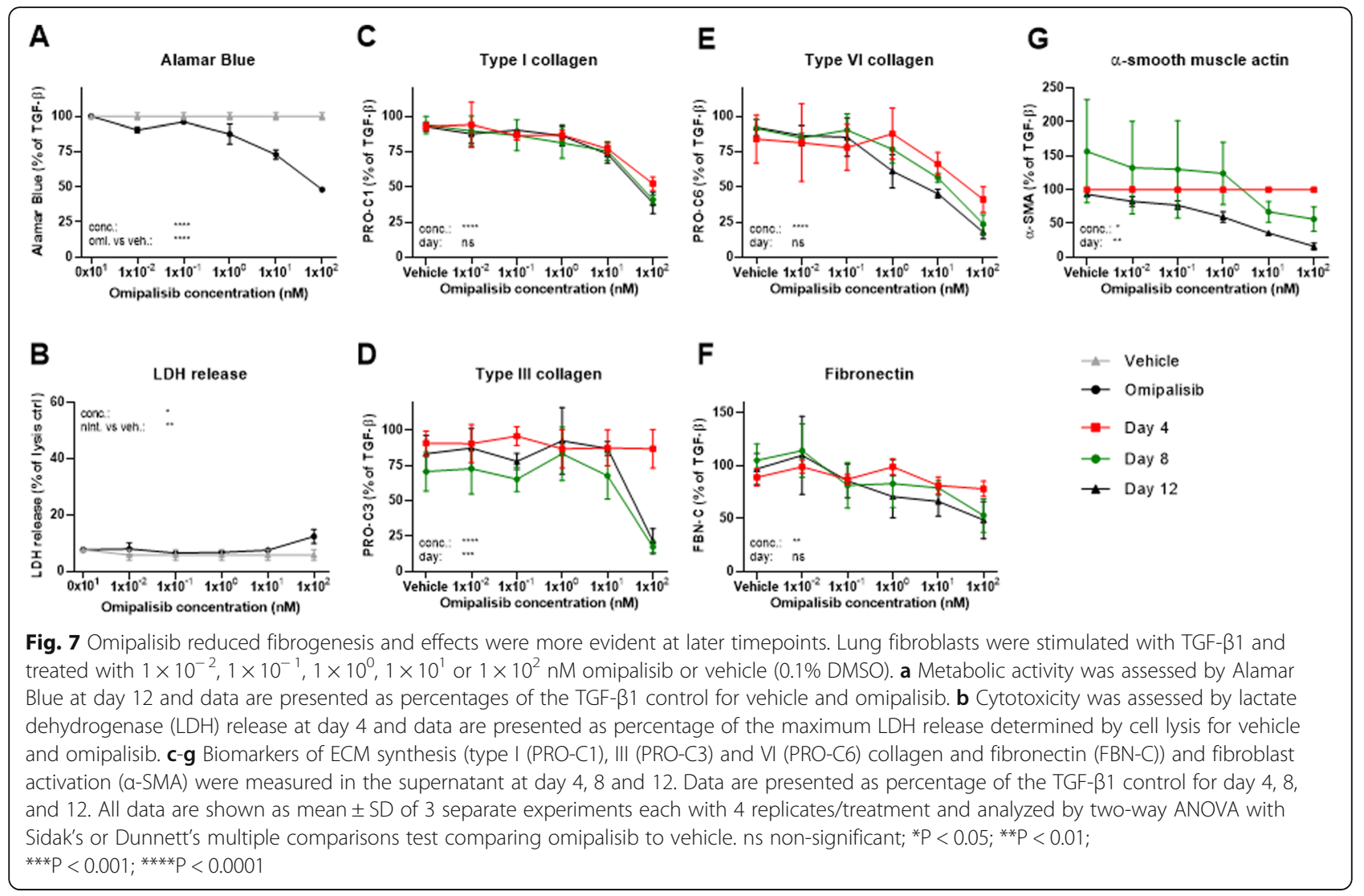

$1000 \mu \mathrm{M}$ [48]. Interestingly, both compounds affected type I collagen fibrils by delaying their formation and resulting in fewer and thinner collagen fibrils as compared with untreated controls. Using the same concentration of pirfenidone in the current assay, anti-fibrotic effects of pirfenidone were evident on fibroblasts although effects were more pronounced for nintedanib and omipalisib. When comparing our data with those published by others, it should be taken into consideration that the biomarkers used to assess ECM protein synthesis in the prolonged Scar-in-a-Jar assay are dependent on the release of collagen pro-peptides to the supernatant during protein maturation. Thus, if changes in the amount of collagen that is laid down in the matrix without proper processing occurred, it would not be registered by the biomarkers. Additionally, any effect on fibrosis resolution, which may be enhanced by antifibrotic compounds, may not be assessed in this system.

In our experiments we aimed to test anti-fibrotic drugs at concentrations similar to those achieved in patients. After standard dosing of nintedanib, plasma concentrations of approximately $70 \mathrm{nM}$ may be reached [56] and concentrations of $1-1000 \mathrm{nM}$ were used with only minor cytotoxic effects in this model. In the literature, pirfenidone is applied in concentrations up to $10 \mathrm{mM}$ in vitro [54,57-59] but in an effort to keep within the physiologically relevant range, pirfenidone was applied in concentrations of $30-3000 \mu \mathrm{M}$ as plasma levels may reach concentrations of $80-100 \mu \mathrm{M}$ after standard dosing of pirfenidone [56]. Notably, no marked effects were observed for pirfenidone in concentrations below $300 \mu \mathrm{M}$. These relatively high concentrations of pirfenidone may force an effect in vitro which is not physiologically relevant. A limitation in our assay is that the higher concentrations of pirfenidone required relatively high concentrations of DMSO which in itself had significant cytotoxic effects at the highest used concentration. However, at concentrations of less than $1000 \mu \mathrm{M}$ pirfenidone, effects of the solvent were not evident based on the Alamar blue or LDH release.

Even though the investigated in vitro model does not reproduce the complexity of the lung tissue during IPF, it allows for an efficient investigation of the ECM production by lung fibroblasts that resembles the process in vivo, since growing the fibroblast in a ficoll-rich moiety ensures that collagens are deposited in the matrix in the natural conformation [33]. Collagen pro-peptides are cleaved off to allow for correct processing and maturation, including cross-linking. However, a simple single-cell culture which does not include other cell types or production of all relevant proteinases is limited in the investigation of the fibrolytic aspect of collagen turnover. Another limitation of the model is the use of a single pro-fibrotic 
stimulus, meaning that anti-fibrotic compounds tested in the current model will need to work through the TGF- $\beta 1$ signaling pathway. Future experiments should investigate the use of other pro-fibrotic mediators, including PDGF, to extend the current model to better represent fibrogenesis. The presented experiments consists of only a few healthy donors of lung fibroblasts, even though the experiment was performed three times to account for technical variability and showed excellent reproducibility. Fibroblasts originating from a range of healthy donors, as well as IPF patients, should be evaluated for their fibrotic response in the prolonged Scar-in-a-Jar model to ensure a continuously working and consistent model.

\section{Conclusions}

In conclusion, the combination of a prolonged Scar-in-aJar model with clinically validated biomarkers of ECM synthesis and the evaluation of anti-fibrotic treatments already approved by the FDA, allowed us to develop a robust fibroblast model to use as a screening tool in early drug development for IPF. Additionally, we have shown the importance of the temporal aspect when evaluating ECM accumulation and that more long-term effects should be assessed. This tool may enable the selection of drug candidates and aid translational science, potentially favoring a more successful path in drug development.

\section{Supplementary information}

Supplementary information accompanies this paper at https://doi.org/10. 1186/s12931-020-01369-1.

Additional file 1: Figure S1. Effect of pirfenidone shown by day. Lung fibroblasts were stimulated with TGF- $\beta 1$ and treated with $3 \times 10^{1}, 1 \times 10^{2}$, $3 \times 10^{2}$ or $1 \times 10^{3} \mu \mathrm{M}$ pirfenidone or corresponding vehicle $(0.03,0.1,0.3$ or $1 \%$ DMSO). Biomarkers of ECM synthesis (type I (PRO-C1), III (PRO-C3) and VI (PRO-C6) collagen and fibronectin (FBN-C)) and fibroblast activation (a-SMA) were measured in the supernatant at day 4, 8 and 12. Data are shown as dose-response curves for pirfenidone and its vehicle for the different timepoints and are presented as percentage of the TGF- $\beta 1$ control over time. All data are shown as mean \pm SD of 3 separate experiments each with 4 replicates/treatment and analyzed by two-way ANOVA with Sidak's multiple comparisons test comparing piffenidone to vehicle. ns non-significant; ${ }^{*} P<0.05 ;{ }^{* *} P<0.01 ;{ }^{* *} P<0.001 ;{ }^{* * *} P<0.0001$.

\section{Abbreviations}

ALK5: Activin receptor-like kinase 5; ALK5i: ALK5/type I TGF- $\beta$ receptor kinase inhibitor; AUC: Area under the curve; BAPN: Beta-aminopropionitrile; DMEM: Dulbecco's modified eagle medium; DMSO: Dimethyl sulfoxide; ECM: Extracellular matrix; ELISA: Enzyme-linked immunosorbent assay; EMA: European Medicines Agency; FBN-C: ELISA assessing fibronectin; FBS: Fetal bovine serum; FDA: U.S. Food and Drug Administration; IPF: Idiopathic pulmonary fibrosis; LDH: Lactate dehydrogenase; LOX: Lysyl oxidase; mTOR: Mammalian target of rapamycin; PBS: Phosphate-buffered saline; PDGF: Platelet-derived growth factor; PI3K: Phosphatidylinositol 3kinase; PRO-C1: ELISA assessing type I collagen formation; PRO-C3: ELISA assessing type III collagen formation; PRO-C4: ELISA assessing 75 domain of type IV collagen; PRO-C5: ELISA assessing type V collagen formation; PROC6: ELISA assessing type VI collagen formation; PROFILE: Prospective Observation of Fibrosis in the Lung Clinical Endpoints; TGF- $\beta 1$ : Transforming growth factor beta 1; aCTX-1: ELISA assessing cross-linking in the C-terminal telopeptide of type I collagen; a-SMA: alpha-smooth muscle actin

\section{Acknowledgements}

The authors would like to acknowledge the technical staff who contributed significantly to the performance of the assay and the biomarker measurements.

\section{Authors' contributions}

SRR, FG, CN, SB, SC, MAK, DJL and JMBS provided substantial contributions to study conception and design. SRR, RQD, HJ and JMBS performed data acquisition and/or data analysis. SRR and JMBS drafted the manuscript. All authors contributed to data interpretation and revised, read and approved the final manuscript.

\section{Funding}

This study was supported by the Danish Agency for Science, Technology and Innovation and the Danish Research Foundation. The funders were not involved in the study design, data analysis and interpretation, manuscript preparation or the decision to publish.

\section{Availability of data and materials}

The datasets used and/or analyzed during the current study are available from the corresponding author on reasonable request.

Ethics approval and consent to participate Not applicable.

\section{Consent for publication}

Not applicable.

\section{Competing interests}

SRR, RQD, FG, HJ, MAK, DJL and JMBS are employees at Nordic Bioscience, and MAK and DJL are shareholders. CBN, VJB and RBG are employees and shareholders at GlaxoSmithKline. SB and SC are employees at Grünenthal. GLS has no competing interests.

\section{Author details}

${ }^{1}$ Nordic Bioscience A/S, Herlev, Herlev Hovedgade 205-207, DK-2730 Herlev, Denmark. ${ }^{2}$ Department of Cancer and Inflammation Research, Institute of Molecular Medicine, University of Southern Denmark, Odense, Denmark. ${ }^{3}$ Department of Fibrosis DPU, Respiratory TA, GlaxoSmithKline, Stevenage, UK. ${ }^{4}$ Innovative Medicines Unit, Grünenthal Innovation, Aachen, Germany.

${ }^{5}$ Present Address: Medicines Discovery Catapult, Alderley Edge, Cheshire, UK.

${ }^{6}$ Present Address: TherapeutAix AG, Aachen, Germany.

Received: 4 August 2019 Accepted: 22 April 2020

Published online: 07 May 2020

\section{References}

1. Froidure A, Joannes A, Mailleux AA, Crestani B. New targets in idiopathic pulmonary fibrosis: from inflammation and immunity to remodeling and repair. Expert Opin Orphan Drugs. 2016;4:511-20.

2. Datta A, Scotton CJ, Chambers RC. Novel therapeutic approaches for pulmonary fibrosis. Br J Pharmacol. 2011;163:141-72.

3. Richeldi L, Collard HR, Jones MG. Idiopathic pulmonary fibrosis. Lancet. 2017;389:1941-52

4. Wynn TA. Integrating mechanisms of pulmonary fibrosis. J Exp Med. 2011 208:1339-50.

5. Caminati A, Madotto F, Cesana G, Conti S, Harari S. Epidemiological studies in idiopathic pulmonary fibrosis: pitfalls in methodologies and data interpretation. Eur Respir Rev. 2015:24:436-44.

6. Hutchinson J, Fogarty A, Hubbard R, McKeever T. Global incidence and mortality of idiopathic pulmonary fibrosis: a systematic review. Eur Respir J. 2015;46:795-806.

7. Hopkins RB, Burke N, Fell C, Dion G, Kolb M. Epidemiology and survival of idiopathic pulmonary fibrosis from national data in Canada. Eur Respir J. 2016:48:187-95.

8. Maher TM, Evans IC, Bottoms SE, Mercer PF, Thorley AJ, Nicholson AG, Laurent GJ, Tetley TD, Chambers RC, McAnulty RJ. Diminished prostaglandin E2 contributes to the apoptosis paradox in idiopathic pulmonary fibrosis. Am J Respir Crit Care Med. 2010;182:73-82.

9. Chapman HA. Epithelial-mesenchymal interactions in pulmonary fibrosis. Annu Rev Physiol. 2011;73:413-35. 
10. Smitha B, Donoghue M. Clinical and histopathological evaluation of collagen fiber orientation in patients with oral submucous fibrosis. J Oral Maxillofac Pathol. 2011;15:154-60.

11. Leeming DJ, Sand JM, Nielsen MJ, Genovese F, Martinez FJ, Hogaboam CM, Han MK, Klickstein LB, Karsdal MA. Serological investigation of the collagen degradation profile of patients with chronic obstructive pulmonary disease or idiopathic pulmonary fibrosis. Biomark Insights. 2012;7:119-26.

12. Karsdal MAA, Nielsen SH, Leeming DJJ, Langholm LLL, Nielsen MJJ, ManonJensen T, Siebuhr A, Gudmann NSS, Rønnow S, Sand JMM, Daniels SJJ, Mortensen $\mathrm{JHH}$, Schuppan D. The good and the bad collagens of fibrosis their role in signaling and organ function. Adv Drug Deliv Rev. 2017;121:4356.

13. Jenkins RG, Simpson JK, Saini G, Bentley JH, Russell AM, Braybrooke R, Molyneaux PL, McKeever TM, Wells AU, Flynn A, Hubbard RB, Leeming DJ, Marshall RP, Karsdal MA, Lukey PT, Maher TM. Longitudinal change in collagen degradation biomarkers in idiopathic pulmonary fibrosis: an analysis from the prospective, multicentre PROFILE study. Lancet Respir Med. 2015;3:462-72.

14. Inchingolo R, Varone F, Sgalla G, Richeldi L. Existing and emerging biomarkers for disease progression in idiopathic pulmonary fibrosis. Expert Rev Respir Med. 2019;13:39-51.

15. Drakopanagiotakis F, Wujak L, Wygrecka M, Markart P. Biomarkers in idiopathic pulmonary fibrosis. Matrix Biol. 2018;68-69:404-21.

16. Martinez FJ, Collard HR, Pardo A, Raghu G, Richeldi L, Selman M, Swigris JJ, Taniguchi H, Wells AU. Idiopathic pulmonary fibrosis. Nat Rev Dis Prim. 2017;3:17074.

17. Richeldi L, Cottin V, du Bois RM, Selman M, Kimura T, Bailes Z, SchlenkerHerceg R, Stowasser S, Brown KK. Nintedanib in patients with idiopathic pulmonary fibrosis: combined evidence from the TOMORROW and INPULSIS $\left({ }^{\oplus}\right)$ trials. Respir Med. 2016;113:74-9.

18. Noble PW, Albera C, Bradford WZ, Costabel U, du Bois RM, Fagan EA, Fishman RS, Glaspole I, Glassberg MK, Lancaster L, Lederer DJ, Leff JA, Nathan SD, Pereira CA, Swigris JJ, Valeyre D, King TE. Pirfenidone for idiopathic pulmonary fibrosis: analysis of pooled data from three multinational phase 3 trials. Eur Respir J. 2016;47:243-53.

19. Somogyi V, Chaudhuri N, Torrisi SE, Kahn N, Müller V, Kreuter M. The therapy of idiopathic pulmonary fibrosis: what is next? Eur Respir Rev. 2019;28.

20. Bahudhanapati $H$, Kass DJ. Unwinding the collagen fibrils: elucidating the mechanism of Pirfenidone and Nintedanib in pulmonary fibrosis. Am J Respir Cell Mol Biol. 2017;57:10-1.

21. Yates DH. mTOR treatment in lymphangioleiomyomatosis: the role of everolimus. Expert Rev Respir Med. 2016;10:249-60.

22. Taveira-DaSilva AM, Moss J. Clinical features, epidemiology, and therapy of lymphangioleiomyomatosis. Clin Epidemiol. 2015;7:249-57.

23. Gao Y, XU X, Ding K, Liang Y, Jiang D, Dai H. Rapamycin inhibits transforming growth factor $\beta 1$-induced fibrogenesis in primary human lung fibroblasts. Yonsei Med J. 2013;54:437-44.

24. Mercer PF, Woodcock HV, Eley JD, Platé M, Sulikowski MG, Durrenberger PF, Franklin L, Nanthakumar CB, Man Y, Genovese F, McAnulty RJ, Yang S, Maher TM, Nicholson AG, Blanchard AD, Marshall RP, Lukey PT, Chambers RC. Exploration of a potent PI3 kinase/mTOR inhibitor as a novel anti-fibrotic agent in IPF. Thorax. 2016;71:701-11.

25. Lukey PT, Harrison SA, Yang S, Man Y, Holman BF, Rashidnasab A, Azzopardi G, Grayer M, Simpson JK, Bareille P, Paul L, Woodcock HV, Toshner R, Saunders P, Molyneaux PL, Thielemans K, Wilson FJ, Mercer PF, Chambers RC, Groves AM, Fahy WA, Marshall RP, Maher TM. A randomised, placebocontrolled study of omipalisib (PI3K/mTOR) in idiopathic pulmonary fibrosis. Eur Respir J. 2019;53:1801992.

26. Nanthakumar CB, Eley J, Man Y, Gudmann NS, Chambers RC, Blanchard A, Fahy W, Maher TM. Omipalasib modulates extracellular matrix turnover in IPF patients: exploratory biomarker analysis from a phase I proof of mechanism study. Am J Respir Crit Care Med. 2019;199:A7301. https://www. atsjournals.org/doi/abs/10.1164/ajrccm-conference.2019.199.1_ MeetingAbstracts.A7301.

27. Woodcock HV, Eley JD, Guillotin D, Platé M, Nanthakumar CB, Martufi M, Peace S, Joberty G, Poeckel D, Good RB, Taylor AR, Zinn N, Redding M, Forty EJ, Hynds RE, Swanton C, Karsdal M, Maher TM, Bergamini G, Marshall RP, Blanchard AD, Mercer PF, Chambers RC. The mTORC1/4E-BP1 axis represents a critical signaling node during fibrogenesis. Nat Commun. 2019; 10:6.
28. Sundarakrishnan A, Chen Y, Black LD, Aldridge BB, Kaplan DL. Engineered cell and tissue models of pulmonary fibrosis. Adv Drug Deliv Rev. 2018;129: 78-94.

29. Chua F, Gauldie J, Laurent GJ. Pulmonary fibrosis: searching for model answers. Am J Respir Cell Mol Biol. 2005;33:9-13.

30. Edmondson R, Broglie JJ, Adcock AF, Yang L. Three-dimensional cell culture systems and their applications in drug discovery and cell-based biosensors. Assay Drug Dev Technol. 2014;12:207-18.

31. Chen CZC, Peng YX, Wang ZB, Fish PV, Kaar JL, Koepsel RR, Russell AJ, Lareu $\mathrm{RR}$, Raghunath $\mathrm{M}$. The scar-in-a-jar: studying potential antifibrotic compounds from the epigenetic to extracellular level in a single well. $\mathrm{Br} J$ Pharmacol. 2009;158:1196-209.

32. Hall D, Minton AP. Macromolecular crowding: qualitative and semiquantitative successes, quantitative challenges. Biochim Biophys Acta. 1649:2003:127-39.

33. Lareu RR, Arsianti I, Subramhanya HK, Yanxian P, Raghunath M. In vitro enhancement of collagen matrix formation and crosslinking for applications in tissue engineering: a preliminary study. Tissue Eng. 2007;13:385-91.

34. Good RB, Eley JD, Gower E, Butt G, Blanchard AD, Fisher AJ, Nanthakumar CB. A high content, phenotypic 'scar-in-a-jar' assay for rapid quantification of collagen fibrillogenesis using disease-derived pulmonary fibroblasts. BMC Biomed Eng. 2019;1:14.

35. Organ LA, Duggan A-MR, Oballa E, Taggart SC, Simpson JK, Kang'ombe AR, Braybrooke R, Molyneaux PL, North B, Karkera Y, Leeming DJ, Karsdal MA, Nanthakumar CB, Fahy WA, Marshall RP, Jenkins RG, Maher TM. Biomarkers of collagen synthesis predict progression in the PROFILE idiopathic pulmonary fibrosis cohort. Respir Res. 2019;20:148.

36. Holm Nielsen S, Willumsen N, Leeming DJ, Daniels SJ, Brix S, Karsdal MA Serological assessment of activated fibroblasts by alpha-smooth muscle actin (a-SMA ): a noninvasive biomarker of activated fibroblasts in lung disorders. Transl Oncol. 2019;12:368-74.

37. Leeming DJ, Larsen DV, Zhang C, Hi Y, Veidal SS, Nielsen RH, Henriksen K Zheng Q, Barkholt V, Riis BJ, Byrjalsen I, Qvist P, Karsdal MA. Enzyme-linked immunosorbent serum assays (ELISAs) for rat and human N-terminal propeptide of collagen type I (PINP) - assessment of corresponding epitopes. Clin Biochem. 2010:43:1249-56.

38. Nielsen MJ, Nedergaard AF, Sun S, Veidal SS, Larsen L, Zheng Q, Suetta C, Henriksen K, Christiansen C, Karsdal MA, Leeming DJ. The neo-epitope specific PRO-C3 ELISA measures true formation of type III collagen associated with liver and muscle parameters. Am J Transl Res. 2013;5:303-15.

39. Leeming DJ, Nielsen MJ, Dai Y, Veidal SS, Vassiliadis E, Zhang C, He Y, Vainer B, Zheng $\mathrm{Q}$, Karsdal MA. Enzyme-linked immunosorbent serum assay specific for the 7S domain of collagen type IV (P4NP 7S): a marker related to the extracellular matrix remodeling during liver fibrogenesis. Hepatol Res. 2012:42:482-93.

40. Vassiliadis $E$, Veidal SS, Simonsen $H$, Larsen DV, Vainer B, Chen X, Zheng Q, Karsdal MA, Leeming DJ. Immunological detection of the type $V$ collagen propeptide fragment, PVCP-1230, in connective tissue remodeling associated with liver fibrosis. Biomarkers. 2011;16:426-33.

41. Leeming DJ, Veidal SS, Karsdal MA, Nielsen MJ, Trebicka J, Busk T, Bendtsen F, Krag A, Møller S. Pro-C5, a marker of true type $V$ collagen formation and fibrillation, correlates with portal hypertension in patients with alcoholic cirrhosis. Scand J Gastroenterol. 2015;50:584-92.

42. Sun S, Henriksen K, Karsdal MA, Byrjalsen I, Rittweger J, Armbrecht G, Belavy DL, Felsenberg D, Nedergaard AF. Collagen type III and VI turnover in response to long-term immobilization. PLoS One. 2015;10:e0144525.

43. Bager CL, Gudmann N, Willumsen N, Leeming DJ, Karsdal MA, Bay-Jensen AC, Høgdall E, Balslev I, He Y. Quantification of fibronectin as a method to assess ex vivo extracellular matrix remodeling. Biochem Biophys Res Commun. 2016:478:586-91

44. Walker EJ, Heydet D, Veldre T, Ghildyal R. Transcriptomic changes during TGF- $\beta$-mediated differentiation of airway fibroblasts to myofibroblasts. Sci Rep. 2019;9:20377.

45. McAnulty RJ, Campa JS, Cambrey AD, Laurent GJ. The effect of transforming growth factor beta on rates of procollagen synthesis and degradation in vitro. Biochim Biophys Acta. 1991;1091:231-5.

46. Roach KM, Feghali-Bostwick CA, Amrani Y, Bradding P. Lipoxin A4 attenuates constitutive and TGF- $\beta 1$-dependent Profibrotic activity in human lung Myofibroblasts. J Immunol. 2015;195:2852-60.

47. Tuan TL, Song A, Chang S, Younai S, Nimni ME. In vitro fibroplasia: matrix contraction, cell growth, and collagen production of fibroblasts cultured in fibrin gels. Exp Cell Res. 1996;223:127-34. 
48. Knüppel L, Ishikawa Y, Aichler M, Heinzelmann K, Hatz R, Behr J, Walch A, Bächinger HP, Eickelberg O, Staab-Weijnitz CA. A novel Antifibrotic mechanism of Nintedanib and Pirfenidone. Inhibition of collagen fibril assembly. Am J Respir Cell Mol Biol. 2017:57:77-90.

49. Epstein Shochet G, Wollin L, Shitrit D. Fibroblast-matrix interplay: Nintedanib and pirfenidone modulate the effect of IPF fibroblast-conditioned matrix on normal fibroblast phenotype. Respirology. 2018;23:756-63.

50. Hostettler KE, Zhong J, Papakonstantinou E, Karakiulakis G, Tamm M, Seidel P, Sun Q, Mandal J, Lardinois D, Lambers C, Roth M. Anti-fibrotic effects of nintedanib in lung fibroblasts derived from patients with idiopathic pulmonary fibrosis. Respir Res. 2014;15:157.

51. Richeldi L, Varone F, Bergna M, de Andrade J, Falk J, Hallowell R, Jouneau S, Kondoh Y, Morrow L, Randerath W, Strek M, Tabaj G. Pharmacological management of progressive-fibrosing interstitial lung diseases: a review of the current evidence. Eur Respir Rev. 2018:27:180074.

52. Nakayama S, Mukae H, Sakamoto N, Kakugawa T, Yoshioka S, Soda H, Oku H, Urata Y, Kondo T, Kubota H, Nagata K, Kohno S. Pirfenidone inhibits the expression of HSP47 in TGF-beta1-stimulated human lung fibroblasts. Life Sci. 2008:82:210-7.

53. Kadir S-I, Wenzel Kragstrup T, Dige A, Kok Jensen S, Dahlerup JF, Kelsen J. Pirfenidone inhibits the proliferation of fibroblasts from patients with active Crohn's disease. Scand J Gastroenterol. 2016:51:1321-5.

54. Molina-Molina M, Machahua-Huamani C, Vicens-Zygmunt V, Llatjós R, Escobar I, Sala-Llinas E, Luburich-Hernaiz P, Dorca J, Montes-Worboys A. Anti-fibrotic effects of pirfenidone and rapamycin in primary IPF fibroblasts and human alveolar epithelial cells. BMC Pulm Med. 2018:18:63.

55. Schuett J, Ostermann A, Wollin L. The effect of nintedanib compared to pirfenidone on proliferation of lung fibroblasts from patients with IPF. Eur Respir J. 2015;46:PA3846.

56. Wollin L, Schuett J, Ostermann A. The effect of nintedanib compared to pirfenidone on serum-stimulated proliferation of human primary lung fibroblasts at clinically relevant concentrations. Am J Resp Crit Care Med. 2015:A4940 at https://www.atsjournals.org/doi/abs/10.1164/ajrccmconference.2015.191.1_MeetingAbstracts.A4940. Accessed 6 Jan 2020.

57. Shin J-M, Park J-H, Park I-H, Lee H-M. Pirfenidone inhibits transforming growth factor $\beta 1$-induced extracellular matrix production in nasal polypderived fibroblasts. Am J Rhinol Allergy. 2015;29:408-13. https://pubmed. ncbi.nIm.nih.gov/26637578/.

58. Kurita Y, Araya J, Minagawa S, Hara H, Ichikawa A, Saito N, Kadota T, Tsubouchi K, Sato N, Yoshida M, Kobayashi K, Ito S, Fujita Y, Utsumi H, Yanagisawa $\mathrm{H}$, Hashimoto M, Wakui H, Yoshii Y, Ishikawa T, Numata T, Kaneko Y, Asano H, Yamashita M, Odaka M, Morikawa T, Nakayama K, Kuwano K. Pirfenidone inhibits myofibroblast differentiation and lung fibrosis development during insufficient mitophagy. Respir Res. 2017;18:114.

59. Hisatomi K, Mukae H, Sakamoto N, Ishimatsu Y, Kakugawa T, Hara S, Fujita H, Nakamichi S, Oku H, Urata Y, Kubota H, Nagata K, Kohno S. Pirfenidone inhibits TGF- $\beta 1$-induced over-expression of collagen type I and heat shock protein 47 in A549 cells. BMC Pulm Med. 2012;12:24.

\section{Publisher's Note}

Springer Nature remains neutral with regard to jurisdictional claims in published maps and institutional affiliations.

Ready to submit your research? Choose BMC and benefit from:
- fast, convenient online submission
- thorough peer review by experienced researchers in your field
- rapid publication on acceptance
- support for research data, including large and complex data types
- gold Open Access which fosters wider collaboration and increased citations
- maximum visibility for your research: over 100M website views per year
At BMC, research is always in progress.
Learn more biomedcentral.com/submissions

